\title{
Mayo del 68 francés
}

No hay duda de que Mayo del 68 francés constituye uno de los movimientos sociales más destacados del siglo XX. Aunque no fue el único. Cincuenta años atrás (1918), surgió en Córdoba, Argentina, el movimiento estudiantil que reclamaba una nueva universidad y una nueva sociedad, logrando movilizar también, como en París 68, a la sociedad de su país. El movimiento de Córdoba como reforma universitaria trascendió el espacio de la universidad y abrió brechas para un cambio social en Latinoamérica. ¿Los protagonistas de Mayo del 68 francés sabían de Córdoba 1918? Es posible que sí. Si tenemos en cuenta la distinción entre historia y memoria colectiva (Halbwachs, 1997) ${ }^{1}$ se asume que la historia comienza en el punto en donde termina la tradición, en donde se descompone la memoria social. Al recordar y tratar de entender las motivaciones de Córdoba (1918) y Mayo del 68 (1968) surge un pluralismo interpretativo. Ver los hechos a distancia provoca una crisis de lo vivido y concebido en el momento mismo de los hechos. Eso lo podemos apreciar en la entrevista que Michel Wieviorka le hace a Edgar Morin alrededor de los hechos de Mayo del 68, de la escritura (en coautoría) de la Brèche y en la evaluación que él mismo hace de su propia participación -e interpretación-en dichos hechos/ momentos, comparándolos con los de sus colegas y contemporáneos. Uno de los intelectuales más destacados del ámbito francés, Raymond Aron, fue víctima de los ataques de los indignados $\mathrm{y}$ de aquellos que vieron en la manifestación de Mayo, una revolución, un cambio, un vuelco en la historia, cuando él, en declaraciones a la prensa y en su libro La Révolution introuvable, Réflexions sur les événements de Mai niega tal revolución y califica la histeria colectiva de 'psicodrama'. Sartre entró también en escena e hizo parte del ataque escribiendo un texto incendiario: Les Bastilles de Raymond Aron, cuya conclusión deslumbro a los indignados de la época: Il faut, maintenant que la France entière a vu de Gaulle tout un, que les étudiants puissent regarder Raymond Aron tout un. On ne lui rendra ses vêtements que s'il accepte la contestation. Los lectores verán en el artículo de Alain Renaud una evaluación de este caso.

Como parte de los actos del cincuentenario de Mayo del 68 francés, la Universidad de Mans organizó un coloquio (mayo 24 y 25 de 2018) Mai 68: 50 ans! Mémoires, représentations, traces $\mathcal{E}$ (ré)interpretations buscando confirmar si en la Francia actual (y en la sociedad occidental) queda una huella de Mayo del 68. Para tal efecto, propuso considerar cuatro dimensiones: (i) volver a interrogar a los actores y testigos. ¿Qué recuerdos conservan de ese momento excepcional (véase por ejemplo el diálogo entre Daniel Cohn-Bendit, Alain Geismar y Michel Wieviorka en esta sección), ¿cómo se representan ellos hoy en día Mayo del 68?, ¿de qué manera su memoria filtró la experiencia? (ver la entrevista

1 Maurice Halbwachs. 1997. La Mémoire collective. Paris: Albin Michel

2 El capítulo XVIII de las memorias de Raymond Aron titulado «Il ne Nous a pas compris» ou Mai 68 (pp. 471497) describe con detalle un rostro de la polémica. El otro rostro es presentado por el trabajo de Renaud y las demás contribuciones. Esta sección de efemérides va dedicada exclusivamente a Raymond Aron por su postura personal, por haber sabido ser un "spectateur engagé" frente a Mayo del 68. 
de Morin y el diálogo Cohn-Bendit, Geismar \& Wieviorka) (ii) Entender de la mejor manera cómo las memorias individuales y colectivas de los eventos evolucionaron a lo largo del tiempo. Entre los procesos de desdibujamiento, ocultamiento, sedimentación, cristalización, ¿cómo se fue transformando la representación de Mayo del 68?, ¿Qué queda de estos tópicos?, ¿permanecen fieles al suceso o, por el contrario, se han deformado por el paso del tiempo y los cambios en la sociedad? (el análisis de las imágenes ofrecidas por diarios y revistas es objeto de análisis por parte de Audrey Leblanc) (iii) identificar las huellas que se mantienen en la consciencia colectiva actual (el hecho de recordar es una prueba de ello) ${ }^{3}$. ¿Qué saben y sienten las generaciones posteriores a Mayo del 68 de algo que no vivieron?, ¿se sienten herederos, beneficiarios?, (iv) comprender mejor los lazos que se establecen entre las interpretaciones de Mayo del 68 y el contexto de su emergencia (a este respecto, la reflexión de Ferry es más que pertinente). ¿De qué forma ha fluctuado la lectura de Mayo del 68 a través del tiempo? Hay una respuesta a todas las preguntas: Pero ese es un discurso nostálgico y viejo; pues la primera gran lección del mayo francés, inédita en su grandiosidad, consiste en mostrarnos que la Revolución no es una sino varias, y que no siempre es preciso que ella se realice para sentir, no obstante, sus efectos. La irrupción del feminismo, del homosexualismo anticulpabilizante, de la ecología naturista, del movimiento comunitario, antiautoritario, biopolítico, el resquebrajamiento del estalinismo internacional, el surgimiento de nuevas alternativas, de nuevas necesidades, de nuevas capas sociales, son los efectos, las ondas de ese inmenso oleaje del mayo del 68, del otoño caliente italiano, del Tlatelolco mexicano, de los sit-in californianos, de la primavera de Praga ${ }^{4}$.

O la respuesta viene de la poesía. Por eso está presente notre cher pote Prévert de quien Yves Courrière se ocupó ${ }^{5}$ para destacar cosas como: On était le 24 avril 1968, et Prévert apprenait le visage de Daniel Cohn-Bendit [...] Pour manifester sa sympathie au mouvement, il écrivit, á la suite de la nuit des Barricades (du 10 au 11 mai 1968), un violent poème pour stigmatiser la satisfaction du préfet de police, Maurice Grimaud, qui se réjouissait du sangfroid des policiers et déplorait l'irresponsabilité des étudiants qu'il soupçonnait d'avoir volontairement provoqué des affrontements avec la police.

3 En 1986, la revista Pouvoirs dedica el número 39 a Mayo del 68. Es un número monográfico que tiene una nómina de lujo analizando en retrospectiva las causas y el valor del evento: «C'était quoi, Mai 68?» Ce numéro a d'abord pour ambition de confronter les réponses à cette question, posée maintes et maintes fois par les étudiants d'aujourd'hui, alors à peine nés. Ainsi n'y raconte-t-on pas les événements, préférant partir à la recherche de leur sens. Ainsi s'est-on soucié avant tout de la France, même si la vague fut multinationale, pour évoquer ce que l'on connaît, et parce que le mouvement étudiant a été accompagné d'une crise de la société sans équivalent ailleurs. [...] Quoi qu'il en soit, l'entrelacs des désaccords politiques, divergences d'interprétation et affrontements de disciplines éclaire la signification de Mai 68. A cette fin, nous avons voulu confronter les interprétations des « savants " avec celles des « acteurs ». Et pour conclure sur des excuses, plutôt que de les adresser à tel courant ou tel groupe qui aurait pu espérer une reconnaissance plus explicite, on se tournera vers les historiens, délaissés par le principe directeur de ce numéro. Si ces mois de travail pour le réaliser ont confirmé une chose, c'est l'urgence d'un autre colloque, d'une autre publication sur «les événements de Mai $68 »$. Olivier DUHAMEL.

4 Freddy Téllez, 1991. Revolución sin revolución o el mayo francés de 1968. Palimpsestos. Los rostros de la escritura. Bogotá: Universidad Nacional, pp. 109-113.

5 Yves Courrière. 2000. Jacques Prévert. En vérité. Paris: Gallimard, collection Folio. 


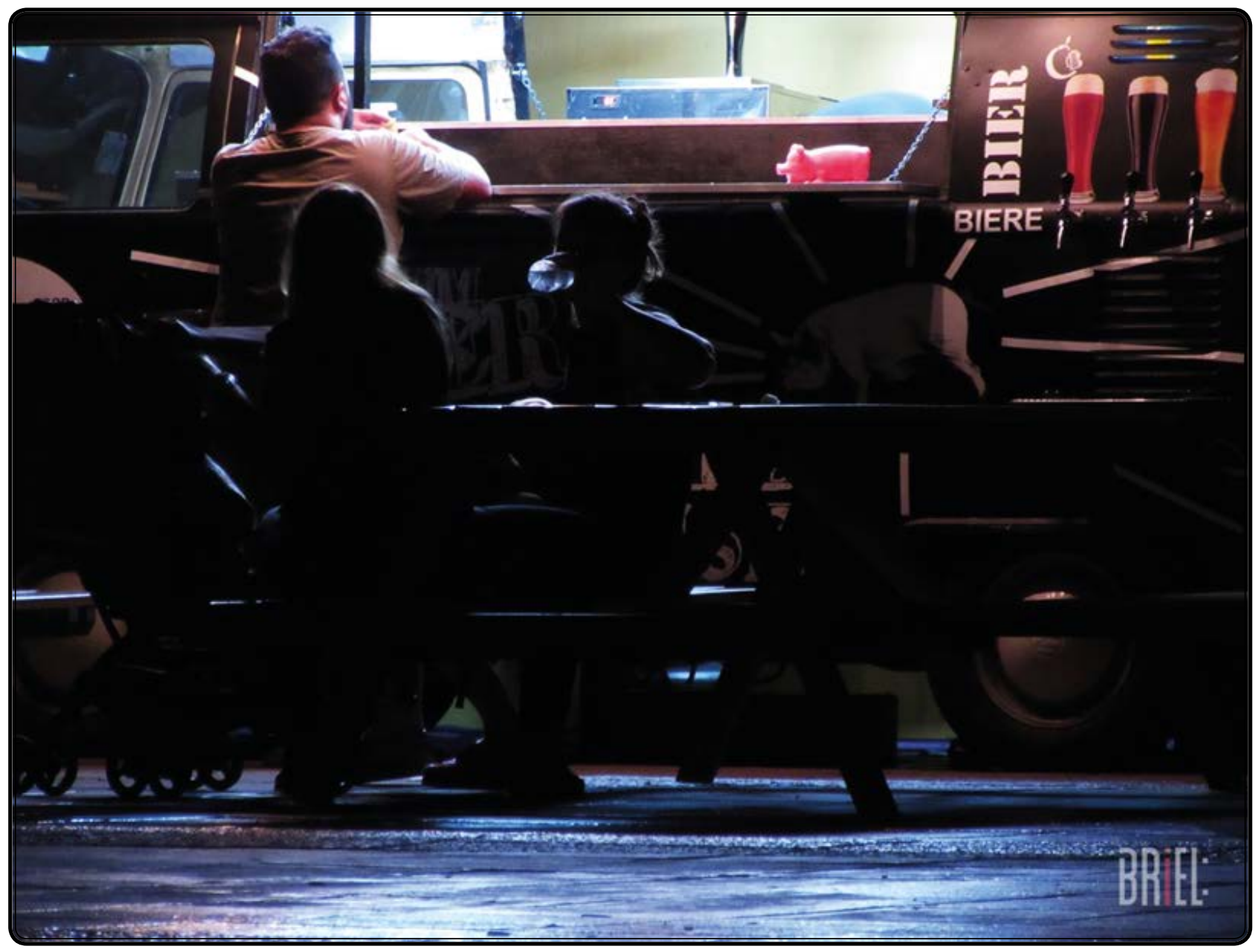

Ranchada. 